\title{
Fear of Movement Is Not Associated With Objective and Subjective Physical Activity Levels in Chronic Nonspecific Low Back Pain
}

\author{
Flávia A. Carvalho, ${ }^{a}$ Chris G. Maher, PhD, ${ }^{b}$ Marcia R. Franco, PhD, ${ }^{a}$ \\ Priscila K. Morelhão, MSc, ${ }^{a}$ Crystian B. Oliveira, MSc, ${ }^{a}$ Fernanda G. Silva, ${ }^{a}$ \\ Rafael Z. Pinto, $\mathrm{PhD}^{\mathrm{a}, \mathrm{b}}$ \\ From the ${ }^{a}$ Physical Therapy Department, Faculty of Science and Technology, São Paulo State University, Presidente Prudente, Brazil; and \\ ${ }^{b}$ Musculoskeletal Division, The George Institute for Global Health, Sydney Medical School, University of Sydney, Sydney, Australia.
}

\begin{abstract}
Objectives: To assess the association of physical activity measures, derived with an accelerometer and a self-reported questionnaire, with fear of movement in patients with chronic nonspecific low back pain (LBP) and to investigate the association between disability and fear of movement in this population.

Design: Cross-sectional study.

Setting: Outpatient physical therapy university clinics.

Participants: Patients $(\mathrm{N}=119)$ presenting with nonspecific LBP of $>3$ months' duration.

Interventions: Not applicable.

Main Outcome Measures: Physical activity levels measured objectively with an accelerometer (ie, counts per minute, time spent in moderateto-vigorous and light physical activity per day, number of steps per day, and number of 10-minute bouts of moderate-to-vigorous physical activity per day) and subjectively with a self-reported questionnaire (Baecke Physical Activity Questionnaire); fear of movement (Tampa Scale of Kinesiophobia); pain (11-point numerical rating scale); disability (Roland Morris Disability Questionnaire); and depression (Beck Depression Inventory). The associations were examined with correlational, univariate, and multivariable linear regression analyses.

Results: None of the objective physical activity measures were associated with fear of movement. The apparent association of self-reported physical activity levels with fear of movement (correlational analyses: $r=-.18 ; P<.05$; univariate regression analyses: $\beta=-.04 ; 95 \%$ confidence interval $[\mathrm{CI}],-.07$ to $-.01 ; P=.04)$ was not confirmed in multivariable analyses. Fear of movement was consistently associated with disability in both correlational $(r=.42 ; P<.01)$ and multivariable $(\beta=.21 ; 95 \% \mathrm{CI}, .11-.31 ; P<.001)$ analyses.

Conclusions: Our data support one aspect of the fear-avoidance model一that higher fear of movement is associated with more disability-but not the aspect of the model linking fear of movement with inactivity.

Archives of Physical Medicine and Rehabilitation 2017;98:96-104

(C) 2016 by the American Congress of Rehabilitation Medicine

In the chronic musculoskeletal pain field, pain-related cognitive and behavioral responses are thought to have a major role in the development and maintenance of chronic or persistent symptoms. $^{1,2}$ To better understand the theoretical relation between

Supported by the São Paulo Research Foundation (grant nos. 2015/17093-7, 2015/07704-9, 2015/02744-2, and 2014/14077-8)

Disclosures: none.

pain-related fear and disability, the fear-avoidance model has been proposed. $^{3}$ This is of importance to the nonspecific low back pain (LBP) field, where in most cases the pathoanatomical source of pain is unknown ${ }^{4}$ and those with chronic symptoms have a poor prognosis. ${ }^{5}$ The fear-avoidance model postulates that higher fear of movement is associated with the development of avoidance behavior, eventually leading to more disability and physical deconditioning (ie, likely due to inactivity or disuse). ${ }^{6}$ The central concept is fear of pain, or the more specific fear that physical
\end{abstract}


activity will cause (re)injury. ${ }^{3}$ A widely used measure of fear of movement in clinical practice and research is the Tampa Scale of Kinesiophobia (TSK). ${ }^{7}$

Several studies have investigated the association between TSK scores and perceived disability measures in patients with chronic LBP. The findings from cross-sectional analyses show fair to moderate correlations between the TSK scores and disability measures, including Roland Morris Disability Questionnaire (RMDQ) $(r=.44-.59),{ }^{8-11}$ Oswestry Disability Index $(r=.50),{ }^{12}$ and Quebec Back Pain Disability Scale $(r=.30-.35) .{ }^{13,14}$ There is also evidence to suggest that this association persists even after controlling for important covariates such as age, sex, and body mass index (BMI). ${ }^{12,15}$ Furthermore, fear of movement, measured by the TSK, has been shown to be an important predictor of chronicity in patients with LBP. ${ }^{16-18}$

Although there is evidence to support the association between fear of movement and disability, the relation between fear of movement and physical deconditioning in patients with chronic LBP is less clear. Previous studies ${ }^{10,12,19}$ have found no association between TSK scores and measures of cardiorespiratory/aerobic fitness, such as walking endurance time ${ }^{12}$ and predicted maximum oxygen consumption $\left(\dot{\mathrm{V}}_{2} \mathrm{max}\right)$ derived from a submaximal bicycle test. ${ }^{10,19}$ In contrast, another study ${ }^{20}$ found a significant negative association between fear of movement and self-reported physical activity levels. A possible explanation for the conflicting evidence is the use of self-reported measures or measures of cardiorespiratory/aerobic fitness to evaluate physical activity levels.

Accelerometers are able to measure and record physical activity in real time, providing more objectivity regarding frequency, intensity, and duration of physical activity with minimal burden on patients. $^{21}$ This method overcomes the reporting bias or recall problems associated with subjective methods, ${ }^{22}$ and compared to other objective methods (eg, $\dot{\mathrm{V}}_{2} \mathrm{max}$ ), it allows the measurement of free-living physical activities during an extended period of time, in real-world rather than laboratory settings. ${ }^{23}$ Nevertheless, to our knowledge, no previous study has used both subjective and objective physical activity measures to examine the association between fear of movement and physical activity levels in chronic LBP. Therefore, the aim of this study was to test the assumption that fear of movement is associated with physical activity levels, measured by objective and subjective methods, in people with chronic nonspecific LBP as well as the assumption that fear of movement is associated with disability in this population.

\section{Methods}

This was a 2-center cross-sectional study. This study was approved by the university ethics research committee (CAAE36332514.0.0000.5402).

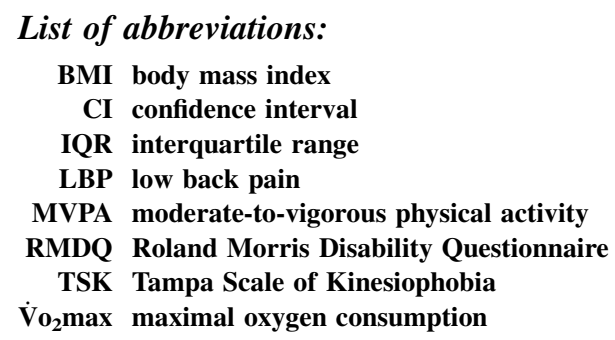

\section{Participants}

Patients with LBP were recruited through advertisements in the community, local press, and social media. Consecutive patients were assessed for eligibility at 2 outpatient physical therapy university clinics in Presidente Prudente, Brazil. Patients aged between 18 and 60 years with chronic nonspecific LBP were considered eligible for the study. Chronic nonspecific $L B P$ was defined as pain and discomfort localized below the costal margin and above the inferior gluteal folds, with or without leg pain of at least 3 months' duration. To be eligible to enter the study, patients had to report moderate-intensity LBP and interference with function as measured by items 7 or 8 of the 36-Item Short Form Health Survey. ${ }^{24}$ Patients presenting with known or suspected serious underlying condition (eg, tumors, fractures, and inflammatory diseases), nerve root compromise (ie, at least 2 of the following signs: weakness, reflex change, or sensation loss associated with the same spinal nerve), history of spinal surgery, cardiorespiratory illnesses, fibromyalgia, any other musculoskeletal condition that may affect activity and movement, pregnancy, illiteracy, or with insufficient understanding of the Portuguese language were excluded.

\section{Procedures}

Each participant attended the physical therapy clinic twice, $\sim 1$ week apart. All participants gave informed consent before data collection. A trained assessor administered the questionnaires during an interview. At the first session, demographic and anthropometric data, duration and severity of LBP, disability, fear of movement, and depression were collected. Participants were asked to wear an accelerometer during waking hours (except when showering, bathing, or swimming) for 7 days after the first session while maintaining their typical weekly schedule. Participants were also asked to record in a diary the times they took off the accelerometer and the reason for doing that to exclude these periods from the analyses. One week later, participants returned the accelerometer.

\section{Data collection}

The following information was collected at the first session:

Demographic and anthropometric data: age, BMI, highest education level, work status, and symptom duration.

Disability: The RMDQ consists of 24 items, with total score ranging from 0 (no disability) to 24 (maximum disability). ${ }^{25,26}$

Pain: The average pain intensity over the last 24 hours was measured with an 11-point numerical rating scale, where 0 denotes no pain and 10 denotes the worst pain imaginable. ${ }^{27}$

Fear of movement: The TSK is a 17-item self-report checklist used to measure fear of movement. Total score ranges from 17 to 68 , with higher scores indicating greater fear of pain and the lowest score 17 indicating no or minimal fear of pain. ${ }^{3,7,28}$ The TSK has shown to have acceptable reliability. ${ }^{29}$

Depression: The Beck Depression Inventory contains 21 items to measure depression symptoms, with scores ranging from 0 (low depression) to 63 (maximum depression). ${ }^{30,31}$

Subjective physical activity measure: The Baecke Habitual Physical Activity Questionnaire is a 16-item self-reported measure of habitual physical activity. Total score ranges from 3 to 15 , with higher scores indicating higher physical activity level. ${ }^{32,33}$ This questionnaire has been shown to have high test-retest reliability in general populations. ${ }^{32}$ 
Objective physical activity measures: Objective measures of physical activity were collected by a triaxial accelerometer. ${ }^{\mathrm{a}}$ This accelerometer is a noninvasive, small, lightweight device $(4.6 \times 3.3 \times 1.5 \mathrm{~cm}, 19 \mathrm{~g})$ that is worn by the patient during waking hours for 7 consecutive days on the right hip. Acceleration data were sampled at $30 \mathrm{~Hz}$ and analyzed at 60 -s epochs. A complete data set for each patient was defined as having at least $10 \mathrm{~h} / \mathrm{d}$ of monitored wear during at least 5 days. ${ }^{34,35}$ We defined nonwear periods as time intervals of at least 60 consecutive minutes of zero counts, with an activity interruption allowance of 0 to 100 counts/min lasting a maximum of 2 consecutive minutes. ${ }^{36}$ The physical activity measures derived from the accelerometer were (1) counts per minute; (2) time spent in light physical activity per day; (3) time spent in moderate-to-vigorous physical activity (MVPA) per day; (4) number of steps per day; and (5) number of 10-minute bouts of MVPA per day. Light physical activity was defined as values between 100 and 2019counts/min, and MVPA was defined as values greater than 2020 counts $/ \mathrm{min}^{34}$ The accelerometer variables were obtained from the vertical axis. Counts per minute were calculated by dividing the sum of activity counts of the vertical axis by the number of valid minutes. ${ }^{34}$ Bouts were defined as $\geq 10$ consecutive minutes above the relevant threshold, allowing interruptions of 1 or 2 minutes below the threshold. ${ }^{34}$ Accelerometer data were analyzed with ActiLife 6 software. ${ }^{a}$

\section{Data analysis}

Descriptive analyses were conducted for the whole cohort and each subgroup defined by sex. Data were presented as frequency (proportion), mean $\pm \mathrm{SD}$, or median (interquartile range [IQR]) depending on the data distribution. The only exception was for physical activity measures, where we opted to report both mean $\pm \mathrm{SD}$ and median (IQR) to allow comparisons with data from published studies. The associations were examined with correlational, univariate, and multivariable linear regression analyses.

For correlational analyses, we calculated the correlation of physical activity measures with fear of movement, pain, and disability as well as the correlation of fear of movement with pain and disability. Bivariate correlations were evaluated with the Pearson correlation coefficient, when both variables analyzed were normally distributed, and with the Spearman rank correlation coefficient, if at least 1 of the variables showed nonnormal distribution. The magnitude of association was interpreted as little or no (from .00 to .25 ), fair (from .25 to .50 ), moderate to good (from .50 to .75$)$, and good to excellent $(>.75)$ relations. ${ }^{37}$

For multivariable linear regression analyses, we conducted separate analyses with a backward elimination approach to investigate the association between each measure of physical activity or disability (ie, dependent variable) and fear of movement (ie, independent variable). The other variables, grouped as personal (age, sex, BMI, symptoms duration, work status, education level) and emotional (depression) factors, were selected a priori as potential covariates. A $\log$ transformation was applied to nonnormally distributed variables. If after $\log$ transformation the variable was still considered nonnormal, we opted to not include the variable in multivariable regression models.

In the first step, we built separate univariate linear regressions for each variable to identify candidates for the multivariable model. Variables considered to be associated with the dependent variable $(P \leq .25)$ were selected for the base model. At this stage, if there were physical activity measures not associated $(P>.25)$ with the TSK, these measures were not evaluated further in multivariable analyses. We also explored whether the interaction between the TSK and age,

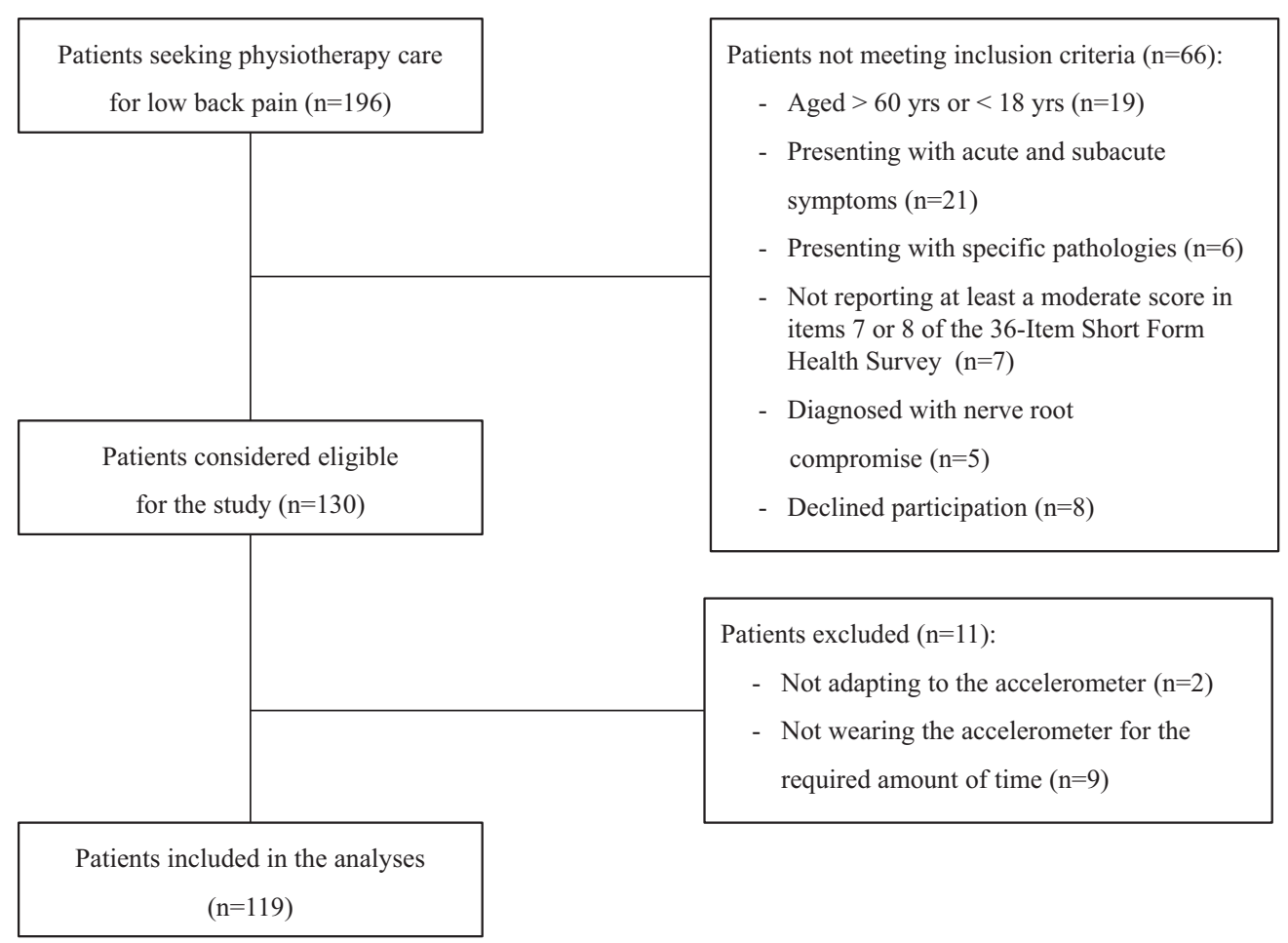

Fig 1 Flow diagram of participants in the study. 
Table 1 Demographic and clinical characteristics of 119 patients and separate data for men and women

\begin{tabular}{|c|c|c|c|}
\hline Characteristic & Sample $(n=119)$ & Women $(n=82)$ & Men $(n=37)$ \\
\hline Age (y) & $39.1 \pm 11.2$ & $38.6 \pm 11.2$ & $40.0 \pm 11.3$ \\
\hline BMI $\left(\mathrm{kg} / \mathrm{m}^{2}\right)$ & $27.1 \pm 7.0$ & $27.0 \pm 7.0$ & $27.5 \pm 7.0$ \\
\hline Symptoms duration (mo) & $12(6.0-48.0)$ & $12.0(6.0-43.5)$ & $24.0(10.0-60.0)$ \\
\hline \multicolumn{4}{|l|}{ Work status } \\
\hline Employed full-time & $24(20.2)$ & $20(24.4)$ & $4(10.8)$ \\
\hline Employed part-time & $49(41.2)$ & $28(34.1)$ & $21(56.7)$ \\
\hline Unemployed & $46(38.7)$ & $34(41.5)$ & $12(32.4)$ \\
\hline \multicolumn{4}{|l|}{ Education } \\
\hline No education beyond primary school* & $23(19.3)$ & $13(15.8)$ & $10(27.0)$ \\
\hline No education beyond secondary school ${ }^{\dagger}$ & $42(35.3)$ & $28(34.1)$ & $14(37.8)$ \\
\hline Tertiary education incomplete & $24(20.2)$ & $17(20.7)$ & $7(18.9)$ \\
\hline Tertiary education complete & $30(25.2)$ & $24(29.2)$ & $6(16.2)$ \\
\hline Fear of movement (TSK, 17-68) & $41.0 \pm 9.0$ & $40.5 \pm 6.3$ & $43.9 \pm 8.4$ \\
\hline Depression (BDI, 0-63) & $11.5 \pm 7.6$ & $12.1 \pm 7.8$ & $10.1 \pm 6.9$ \\
\hline Disability (RMDQ, 0-24) & $12.2 \pm 4.6$ & $12.0 \pm 4.6$ & $13.0 \pm 5.5$ \\
\hline Pain (NRS, 0-10) & $6.7 \pm 1.7$ & $6.7 \pm 1.7$ & $6.5 \pm 1.6$ \\
\hline Self-reported physical activity levels (BPAQ, 3-15) & $6.7 \pm 1.3$ & $6.9 \pm 1.3$ & $6.4 \pm 1.4$ \\
\hline \multicolumn{4}{|l|}{ Accelerometer data } \\
\hline \multirow[t]{2}{*}{ Time spent in MVPA per day } & $21.7 \pm 16.2$ & $22.8 \pm 17.2$ & $19.1 \pm 13.4$ \\
\hline & $17.3(10.2-30.5)$ & $18.1(10.1-31.4)$ & $15.8(10.9-23.0)$ \\
\hline \multirow[t]{2}{*}{ Counts per minute } & $296.1 \pm 111.6$ & $296.7 \pm 111.7$ & $291.6 \pm 113.0$ \\
\hline & $272.4(219.1-342.5)$ & $271.1(227.7-343.8)$ & $283.7(208.4-353.4)$ \\
\hline \multirow[t]{2}{*}{ Number of bouts per day } & $9.9 \pm 9.5$ & $11.0 \pm 8.8$ & $7.7 \pm 11.0$ \\
\hline & $11.5(0.0-14.0)$ & $12.0(0.0-14.5)$ & $0.0(0.0-12.5)$ \\
\hline \multirow[t]{2}{*}{ Number of steps per day } & $6843.7 \pm 2543.9$ & $6913.3 \pm 2413.6$ & $6689.3 \pm 2840.8$ \\
\hline & $6428.0(5183.5-8137.0)$ & $6441.6(5374.4-8178.9)$ & $6395.5(4933.0-7791.4)$ \\
\hline \multirow[t]{2}{*}{ Time spent in light physical activity per day } & $333.4 \pm 89.5$ & $331.7 \pm 82.9$ & $337.0 \pm 102.7$ \\
\hline & $334.0(272.5-389.2)$ & $342.6(271.2-388.3)$ & $317.8(272.6-399.1)$ \\
\hline
\end{tabular}

NOTE. Values are mean $\pm S D$, median (IQR), or $n(\%)$.

Abbreviations: BDI, Beck Depression Inventory; BPAQ, Baecke Habitual Physical Activity Questionnaire; NRS, numerical rating scale.

* In Brazil, primary schools provide education from the age of 5 to 11.

$\dagger$ In Brazil, secondary schools provide education from the age of 12 to 17.

$\ddagger$ For accelerometer data, mean \pm SD and median (IQR) values are reported to allow comparison with data from the literature.

between the TSK and sex, between education level and sex, or between work status and sex affected the results of multivariable models. Statistical assumptions underlying linear regression models were met for all analyses presented, because the residuals showed no indication of nonnormal distribution, heteroscedasticity, and nonlinearity. In addition, there was no indication of multicollinearity because continuous variables were not highly correlated $(r<0.6)$ and the variance inflation factor values were not $>2.0$ in all steps. All statistics were performed using SPSS version $20.0,{ }^{\mathrm{b}}$ with a $P$ value of .05 set as a criterion for the final multivariable model.

\section{Results}

A total of 196 patients were assessed for eligibility between September 1, 2014, and October 15, 2015. Sixty-six (34\%) patients were excluded for not meeting the inclusion criteria and $11(6 \%)$ patients for not adapting to or not correctly wearing the accelerometer for the required amount of time. A final sample including 119 participants with chronic nonspecific LBP was included in the study (fig 1). Our sample was predominantly women (69\%), with a mean age of $40 \pm 19$ years with a median symptom duration of 12 months (IQR, 6-48mo). The detailed characteristics of the whole sample and men/women are listed in table 1.

\section{Correlational analyses}

Correlation coefficients are presented in table 2. The objective physical activity measures showed no association with fear of movement, pain, and disability. Even when the association was statistically significant, the magnitude of association was interpreted as having, at best, little relation $(r<.25)$. Similarly, although the self-reported measure of physical activity levels showed a significant negative association with fear of movement, disability, and pain, the relation varied from little to fair. Disability showed a fair positive association with fear of movement and pain.

\section{Multivariable linear regression analyses}

Because of nonnormal distribution, symptom duration, Time spent in MVPA, and number of steps were log-transformed before inclusion in the multivariable analyses. Number of bouts even after $\log$ transformation remained not normally distributed, so this variable was not further investigated in multivariable analyses. The results of univariate analyses are presented in table 3. Counts, number of steps, and time spent in light physical activity were not associated with the TSK and not further investigated in multivariable analyses. Age, BMI, sex, depression, disability, pain, and work status were associated $(P \leq .25)$ with the Baecke Habitual 
Table 2 Correlation coefficients for the association of fear of movement with PA measures, pain, and disability and for the association of PA measures with pain and disability

\begin{tabular}{lcll}
\hline & $\begin{array}{l}\text { Fear of } \\
\text { Movement } \\
\text { Variable }\end{array}$ & $\begin{array}{l}\text { Disability } \\
\text { (TSM) }\end{array}$ & $\begin{array}{l}\text { Pain } \\
\text { (RRS) }\end{array}$ \\
\hline Disability (RMDQ) & $.42^{*}$ & NA & $.45^{*}$ \\
Pain (NRS) & .17 & $.45^{*}$ & NA \\
Self-reported PA (BPAQ) & $-.18^{\dagger}$ & $-.28^{*}$ & $-.23^{\dagger}$ \\
Accelerometer data & & & \\
$\quad$ Time spent in MVPA per day & -.13 & $-.20^{\dagger}$ & -.08 \\
Time spent in LPA per day & .09 & -.01 & -.04 \\
Counts per minute & -.02 & -.06 & -.05 \\
$\quad$ Number of bouts per day ${ }^{\ddagger}$ & -.17 & $-.22^{\dagger}$ & -.01 \\
$\quad$ Number of steps per day & -.15 & .01 & -.06 \\
\hline
\end{tabular}

NOTE. Disability showed significant fair (from .25 to .50) positive association with fear of movement and pain and significant fair negative association with self-reported PA. Correlation coefficients presented were calculated using the Pearson correlation method unless otherwise indicated.

Abbreviations: BPAQ, Baecke Habitual Physical Activity Questionnaire; LPA, light physical activity; NA, not applicable; NRS, numerical rating scale; PA, physical activity.

* Correlation is significant at the .01 level (2-tailed).

$\dagger$ Correlation is significant at the .05 level (2-tailed).

$¥$ Because of nonnormal distribution, correlation coefficients for the specific variable were calculated using the Spearman rank correlation method.

Physical Activity Questionnaire, whereas BMI and disability were associated with time spent in MVPA. Variables showing association with dependent variables (ie, Baecke Habitual Physical Activity Questionnaire, time spent in MVPA, and disability) were considered as potential covariates for the multivariable models. None of the interaction terms were found to improve the model.

The results of multivariable regression analyses with Baecke Habitual Physical Activity Questionnaire, time spent in MVPA, and disability as dependent variables, TSK as the independent variable, and all potential covariates are presented in table 4 . The base model represents the starting model, and the final model is the model after elimination of all nonsignificant variables. The results show that none of the physical activity measures (ie, Baecke Habitual Physical Activity Questionnaire and time spent in MVPA) investigated in multivariable analyses were associated with the TSK after controlling for potential covariates. The final model for the Baecke Habitual Physical Activity Questionnaire including disability, BMI, and age explained $14 \%$ of the total variance. For time spent in MVPA, none of the variables included in the base model were significant in the final model. In the multivariable model for disability, fear of movement remained significant in the final model after controlling for covariates. The final model, including age, BMI, numerical rating scale, TSK, Baecke Habitual Physical Activity Questionnaire, and work status, explained $44 \%$ of the total variance in disability.

\section{Discussion}

Our findings showed that objective physical activity measures are not associated with fear of movement in people with chronic nonspecific LBP. Our results also revealed that the apparent association between self-reported physical activity and fear of movement was not confirmed in multivariable analyses. Not surprisingly, disability was found to be associated with fear of movement even after controlling for potential confounders. Our data support the part of the fear-avoidance model stating that higher fear of movement leads to more disability. However, our analysis challenges the part of the model suggesting that fear of movement is associated with inactivity.

Three previous studies ${ }^{10,12,19}$ conducting univariate or multivariate regression analyses found no association between fear of movement and objective measures of aerobic fitness (ie, $\dot{\mathrm{V}}_{\mathrm{O}_{2}} \mathrm{max}$ and walking endurance). Our study using accelerometers that allow the objective measurement of free-living physical activities showed somewhat similar findings, suggesting that patients who report high fear of movement do not necessarily have low objective physical activity levels. In contrast, a previous study ${ }^{20}$ found a negative association between fear of movement and self-reported physical activity after controlling for age. In the present study, our findings suggest little relation between selfreported physical activity and fear of movement. This apparent association, however, was not confirmed in multivariable analyses. To our knowledge, this is the first study to explore whether the association between fear of movement and physical activity levels vary depending on the assessment method. Our findings suggest that regardless of the physical activity assessment method, patients reporting higher fear of movement did not show lower levels of physical activity.

Although our findings support the association between disability and fear of movement, we could not confirm the fearavoidance model's assumption that high levels of fear of movement are associated with lower physical activity levels in people with chronic LBP. Although the fear-avoidance model implies that fear of movement is associated with both disability and physical activity levels, important conceptual differences exist between the two. Perceived disability is often measured by questionnaires that cover a range of spine-related functions (eg, twisting, bending over, and sitting) likely to be affected by LBP, whereas subjective and objective physical activity assessment methods provide a global measure of the patient's level of physical activity. Therefore, one interpretation is that patients having higher fear of movement would avoid spine-related functions, such as those tasks described in the RMDQ, but would remain physically active during their daily routine. It is still debatable in the LBP field whether chronic pain leads to inactivity. ${ }^{38,39}$ Interestingly, the male participants in our sample (292counts/min; $95 \%$ confidence interval $[\mathrm{CI}], 255-327$ counts/min) were considered less active than the American adult population ${ }^{40}$ (377counts/min; 95\% CI, 363-391counts/min), whereas the female participants' physical activity levels (297counts/min; 95\% CI, 273-321counts/min) in our sample did not differ from those of the American population ${ }^{40}$ (298counts/min; 95\% CI, 289-307counts/min). A potential factor that can make it difficult to compare studies is the actual physical activity level of the sample. A recent study $^{41}$ from a related chronic pain field showed that having knee osteoarthritis is associated with a varying degree of physical activity patterns in different countries. If these data apply to the LBP field, it may explain why there is not a clear pattern in previous studies.

Recently, criticisms of the fear-avoidance model have emerged. Wideman et $\mathrm{al}^{42}$ argued that the proposed cyclical pathway in the fear-avoidance model might be too simplistic to understand how its components interact with each other. Recent 
Table 3

Univariate regression analyses for the identification of candidate variables for multivariable regression models

\begin{tabular}{|c|c|c|c|c|c|c|c|c|c|c|c|c|}
\hline \multirow[b]{2}{*}{ Variable } & \multicolumn{2}{|c|}{ Self-Reported PA (BPAQ) } & \multicolumn{2}{|c|}{$\begin{array}{l}\text { Time spent in } \\
\text { MVPA per Day* }\end{array}$} & \multicolumn{2}{|c|}{ Counts per Minute } & \multicolumn{2}{|c|}{ Number of Steps per Day* } & \multirow{2}{*}{$\begin{array}{l}\text { Time Spent in } \\
\text { LPA per Day } \\
\beta(95 \% \mathrm{CI})\end{array}$} & \multirow[b]{2}{*}{$P$} & \multicolumn{2}{|c|}{ Disability (RMDQ) } \\
\hline & $\beta(95 \% \mathrm{CI})$ & $P$ & $\beta(95 \% \mathrm{CI})$ & $P$ & $\beta(95 \% \mathrm{CI})$ & $P$ & $\beta(95 \% \mathrm{CI})$ & $P$ & & & $\beta(95 \% \mathrm{CI})$ & $P$ \\
\hline $\begin{array}{l}\text { Fear of movement } \\
\text { (TSK) }\end{array}$ & $\begin{array}{l}-0.04 \\
(-0.07 \text { to }-0.01)\end{array}$ & .04 & $\begin{array}{l}-0.01 \\
(-0.02 \text { to } 0.00)\end{array}$ & .14 & $\begin{array}{l}-0.30 \\
(-3.16 \text { to } 2.56)\end{array}$ & .84 & $\begin{array}{l}-0.00 \\
(-0.01 \text { to } 0.00)\end{array}$ & .64 & $\begin{array}{l}1.18 \\
(-1.10 \text { to } 3.46)\end{array}$ & .31 & $\begin{array}{l}0.27 \\
(0.17 \text { to } 0.38)\end{array}$ & $<.001$ \\
\hline Disability (RMDQ) & $\begin{array}{l}-0.08 \\
(-0.13 \text { to }-0.03)\end{array}$ & .00 & $\begin{array}{l}-0.01 \\
(-0.03 \text { to } 0.00)\end{array}$ & .09 & $\begin{array}{l}-0.00 \\
(-0.01 \text { to } 0.01)\end{array}$ & .51 & $\begin{array}{l}-5.86 \\
(-11.07 \text { to }-0.65)\end{array}$ & .03 & $\begin{array}{l}0.00 \\
(-0.01 \text { to } 0.01)\end{array}$ & .95 & NA & NA \\
\hline Age & $\begin{array}{l}0.01 \\
(-0.01 \text { to } 0.03)\end{array}$ & .24 & $\begin{array}{l}0.00 \\
(-0.01 \text { to } 0.00)\end{array}$ & .38 & NA & & NA & & NA & & $\begin{array}{l}0.12 \\
(0.05 \text { to } 0.19)\end{array}$ & .002 \\
\hline BMI & $\begin{array}{l}0.03 \\
(-0.00 \text { to } 0.07)\end{array}$ & .09 & $\begin{array}{l}-0.01 \\
(-0.02 \text { to } 0.01)\end{array}$ & .25 & NA & & NA & & NA & & $\begin{array}{l}0.10 \\
(-0.03 \text { to } 0.22)\end{array}$ & .12 \\
\hline $\operatorname{Sex}^{\dagger}$ & $\begin{array}{l}0.50 \\
(-0.02 \text { to } 1.01)\end{array}$ & .06 & $\begin{array}{c}0.07 \\
(-0.09 \text { to } 0.24)\end{array}$ & .38 & NA & & NA & & NA & & $\begin{array}{l}-0.83 \\
(-2.66 \text { to } 1.01)\end{array}$ & .37 \\
\hline Symptoms duration* & $\begin{array}{l}0.22 \\
(-0.23 \text { to } 0.67)\end{array}$ & .34 & $\begin{array}{l}0.06 \\
(-0.08 \text { to } 0.20)\end{array}$ & .38 & NA & & NA & & NA & & $\begin{array}{l}-0.20 \\
(-1.78 \text { to } 1.38)\end{array}$ & .80 \\
\hline Depression (BDI) & $\begin{array}{l}-0.02 \\
(-0.05 \text { to } 0.01)\end{array}$ & .25 & $\begin{array}{l}0.00 \\
(-0.01 \text { to } 0.01)\end{array}$ & .99 & NA & & NA & & NA & & $\begin{array}{l}0.85 \\
(-0.03 \text { to } 0.20)\end{array}$ & .14 \\
\hline Pain (NRS, $0-10$ ) & $\begin{array}{l}-0.18 \\
(-0.32 \text { to }-0.04)\end{array}$ & .01 & $\begin{array}{l}-0.02 \\
(-0.06 \text { to } 0.03)\end{array}$ & .43 & NA & & NA & & NA & & $\begin{array}{l}1.25 \\
(0.79 \text { to } 1.70)\end{array}$ & $<.001$ \\
\hline Education $^{\dagger}$ & & & & & & & & & & & & \\
\hline $\begin{array}{l}\text { No education } \\
\text { beyond primary } \\
\text { school }\end{array}$ & $\begin{array}{l}0.02 \\
(-0.54 \text { to } 0.94)\end{array}$ & .59 & $\begin{array}{l}-0.01 \\
(-0.24 \text { to } 0.22)\end{array}$ & .94 & NA & & NA & & NA & & $\begin{array}{l}0.79 \\
(-1.77 \text { to } 3.36)\end{array}$ & .54 \\
\hline $\begin{array}{l}\text { No education } \\
\text { beyond } \\
\text { secondary } \\
\text { school }\end{array}$ & $\begin{array}{l}0.19 \\
(-0.45 \text { to } 0.82)\end{array}$ & .56 & $\begin{array}{l}-0.03 \\
(-0.23 \text { to } 0.17)\end{array}$ & .78 & NA & & NA & & NA & & $\begin{array}{l}-0.62 \\
(-2.84 \text { to } 1.59)\end{array}$ & .58 \\
\hline $\begin{array}{l}\text { Tertiary education } \\
\text { incomplete } \\
\text { Work status }^{\dagger}\end{array}$ & $\begin{array}{l}-0.17 \\
(-0.89 \text { to } 0.56)\end{array}$ & .65 & $\begin{array}{l}0.07 \\
(-0.16 \text { to } 0.30)\end{array}$ & .55 & NA & & NA & & NA & & $\begin{array}{l}-1.31 \\
(-3.84 \text { to } 1.23)\end{array}$ & .31 \\
\hline $\begin{array}{l}\text { Employed part- } \\
\text { time }\end{array}$ & $\begin{array}{l}0.84 \\
(0.19 \text { to } 1.49)\end{array}$ & .01 & $\begin{array}{l}0.09 \\
(-1.21 \text { to } 0.29)\end{array}$ & .41 & NA & & NA & & NA & & $\begin{array}{l}-2.27 \\
(-4.56 \text { to } 0.02)\end{array}$ & .05 \\
\hline $\begin{array}{l}\text { Employed full- } \\
\text { time }\end{array}$ & $\begin{array}{c}0.52 \\
\text { (0.01 to } 1.07)\end{array}$ & .04 & $\begin{array}{l}-0.00 \\
(-0.17 \text { to } 0.17)\end{array}$ & .99 & NA & & NA & & NA & & $\begin{array}{l}-1.93 \\
(-3.80 \text { to }-0.06)\end{array}$ & .04 \\
\hline
\end{tabular}

NOTE. Self-reported physical activity and time spent in MVPA were associated $(P<.25)$ with fear of movement and selected as dependent variables for the multivariable regression models. Disability was associated with fear of movement, self-reported physical activity, number of steps, and time spent in MVPA. Other variables associated $(P<.25)$ with dependent variables were selected as covariates.

Abbreviations: $\beta$, unstandardized B coefficient; BDI, Beck Depression Inventory; BPAQ, Baecke Habitual Physical Activity Questionnaire; LPA, light physical activity; NA, not applicable; NRS, numerical rating

scale.

* Variable log-transformed.

Reference categories for sex, education, and work status are male, tertiary education complete, and unemployed, respectively. 
Table 4 Summary of 3 multivariable regression analyses with self-reported PA, time spent in MVPA, and disability as dependent variables, fear of movement as the independent variable of interest, and all potential covariates

\begin{tabular}{|c|c|c|c|c|c|}
\hline Model Steps & Independent Variable or Covariates & $\mathrm{F}$ & $R^{2}$ (Adjusted $R^{2}$ ) & $\beta(95 \% \mathrm{CI})$ & $P$ \\
\hline \multicolumn{6}{|c|}{ Dependent variable: Self-reported PA (BPAQ) } \\
\hline \multirow[t]{11}{*}{ Base model } & (Constant) & 3.61 & $23 \%(17 \%)$ & & .001 \\
\hline & Age & & & $0.02(0.00$ to 0.04$)$ & .02 \\
\hline & Sex & & & $0.48(-0.035$ to 0.99$)$ & .07 \\
\hline & BMI & & & $0.03(-0.00$ to 0.07$)$ & .06 \\
\hline & Depression (BDI) & & & $-0.01(-0.04$ to 0.02$)$ & .63 \\
\hline & Disability (RMDQ) & & & $-0.06(-0.12$ to 0.00$)$ & .06 \\
\hline & Pain (NRS) & & & $-0.09(-0.25$ to 0.54$)$ & .20 \\
\hline & Fear of movement (TSK) & & & $-0.02(-0.05$ to 0.02$)$ & .35 \\
\hline & Work status & & & & \\
\hline & Employed part-time & & & $0.57(-0.07$ to 1.22$)$ & .08 \\
\hline & Employed full-time & & & $-0.36(-0.16$ to 0.18$)$ & .17 \\
\hline \multirow[t]{4}{*}{ Final model } & (Constant) & 7.24 & $16 \%(14 \%)$ & & $<.001$ \\
\hline & Age & & & $0.02(0.00$ to 0.04$)$ & .02 \\
\hline & BMI & & & 0.04 (0.01 to 0.07$)$ & .02 \\
\hline & Disability (RMDQ) & & & $-0.11(-0.16$ to -0.06$)$ & $<.001$ \\
\hline \multicolumn{6}{|c|}{ Dependent variable: Time spent in MVPA per day* } \\
\hline \multirow[t]{4}{*}{ Base model } & (Constant) & 1.52 & $4 \%(1 \%)$ & & $<.001$ \\
\hline & BMI & & & $-0.01(-0.02$ to 0.01$)$ & .33 \\
\hline & Disability (RMDQ) & & & $-0.01(-0.03$ to 0.01$)$ & .31 \\
\hline & Fear of movement (TSK) & & & $-0.01(-0.02$ to 0.01$)$ & .37 \\
\hline Final model & None of the variables remained in $t$ & lal model & & & \\
\hline \multicolumn{6}{|c|}{ Dependent variable: Disability (RMDQ) } \\
\hline \multirow[t]{12}{*}{ Base model } & (Constant) & 8.70 & $45 \%(40 \%)$ & & $<.001$ \\
\hline & Age & & & 0.09 (0.03 to 0.15$)$ & .007 \\
\hline & BMI & & & $0.12(0.02$ to 0.21$)$ & .02 \\
\hline & Depression (BDI) & & & $0.02(-0.08$ to 0.11$)$ & .75 \\
\hline & Pain (NRS) & & & $0.78(0.35$ to 1.21$)$ & .001 \\
\hline & Fear of movement (TSK) & & & $0.21(0.11$ to 0.31$)$ & $<.001$ \\
\hline & Self-reported PA (BPAQ) & & & $-0.51(-1.11$ to 0.09$)$ & .09 \\
\hline & Time spent in MVPA per day* & & & $1.10(-1.28$ to 3.49$)$ & \\
\hline & Number of steps per day* & & & $-3.79(-10.01$ to 2.49$)$ & \\
\hline & Work status & & & & \\
\hline & Employed part-time & & & $-1.98(-3.90$ to -0.07$)$ & .04 \\
\hline & Employed full-time & & & $-1.57(-3.01$ to -0.040$)$ & .04 \\
\hline \multirow[t]{9}{*}{ Final model } & (Constant) & 12.36 & $44 \%(40 \%)$ & & $<.001$ \\
\hline & Age & & & $0.08(0.02$ to 0.14$)$ & .01 \\
\hline & BMI & & & 0.12 (0.26 to 0.22$)$ & .01 \\
\hline & Pain (NRS) & & & 0.84 (0.43 to 1.25$)$ & $<.001$ \\
\hline & Fear of movement (TSK) & & & 0.21 (0.11 to 0.31$)$ & $<.001$ \\
\hline & Self-reported PA (BPAQ) & & & $-0.54(-1.09$ to 0.00$)$ & .04 \\
\hline & Work status & & & & \\
\hline & Employed part-time & & & $-2.12(-4.01$ to -0.24$)$ & .03 \\
\hline & Employed full-time & & & $-1.62(-3.13$ to -0.10$)$ & .04 \\
\hline
\end{tabular}

Abbreviations: $\beta$, unstandardized B coefficient; BPAQ, Baecke Habitual Physical Activity Questionnaire; BDI, Beck Depression Inventory; NRS, numerical rating scale; $\mathrm{PA}$, physical activity.

* Variable log-transformed before inclusion in the model.

findings support a cumulative negative effect of different elevated psychosocial factors (ie, fear of movement, depression, and catastrophizing) on long-term levels of pain and work disability. ${ }^{43,44}$ Another proposed model is the avoidance-endurance model. ${ }^{45}$ Proponents of this model argue that in addition to the fearavoidance response, there is potentially another opposite pathway leading to the development and maintenance of chronic pain. In this alternate pathway, patients develop endurance-related responses, including physical overuse or overload instead of physical disuse as the main mediators. Further research is needed to test these new models of behavior.

\section{Study limitations}

A limitation of this study is the cross-sectional design, which gives limited information about causality. In addition, we have focused 
on only 1 fear-related construct. Given that a recent study ${ }^{46}$ has questioned whether the TSK should be described as a measure of fear of movement/(re)injury, future studies should test the association of physical activity measures with other fear-related constructs, such as pain anxiety, fear-avoidance beliefs, and catastrophizing.

\section{Conclusions}

Fear of movement is not associated with physical activity levels in patients with chronic LBP. The lack of association was found regardless of the physical activity assessment method used, accelerometry, or self-reported questionnaires. In accordance with previous studies, fear of movement was associated with disability. Future studies are needed to fully understand the role of fear of movement, and its interaction with other psychological factors, in the development and persistence of pain-related disability.

\section{Suppliers}

a. Triaxial accelerometer; ActiGraph, LLC.

b. SPSS version 20.0; IBM Corp.

\section{Keywords}

Activities of daily living; Fear; Low back pain; Motor activity; Rehabilitation

\section{Corresponding author}

Rafael Z. Pinto, PhD, Departamento de Fisioterapia, Faculdade de Ciências e Tecnologia, UNESP - Universidade Estadual Paulista, Rua Roberto Simonsen, 305, Presidente Prudente, SP, CEP 19060900, Brazil. E-mail address: rafaelzambelli@gmail.com.

\section{References}

1. Keefe FJ, Dunsmoret J. Pain behavior concepts and controversies. Am Pain Soc J 1992;1:92-100.

2. Turk DC, Rudy TE. Cognitive factors and persistent pain: a glimpse into Pandora's box. Cognit Ther Res 1992;16:99-122.

3. Vlaeyen JW, Crombez G. Fear of movement/(re)injury, avoidance and pain disability in chronic low back pain patients. Man Ther 1999;4: 187-95.

4. Maher CG, Williams C, Lin C, Latimer J. Managing low back pain in primary care. Aust Prescr 2011;34:128-32.

5. da C Menezes Costa L, Maher CG, Hancock MJ, McAuley JH, Herbert RD, Costa LO. The prognosis of acute and persistent low-back pain: a meta-analysis. CMAJ 2012;184:E613-24.

6. Vlaeyen JW, Linton SJ. Fear-avoidance and its consequences in chronic musculoskeletal pain: a state of the art. Pain 2000;85:317-32.

7. Vlaeyen JW, Kole-Snijders AM, Boeren RG, van Eek H. Fear of movement/(re)injury in chronic low back pain and its relation to behavioral performance. Pain 1995;62:363-72.

8. Costa Lda C, Maher CG, McAuley JH, Hancock MJ, Smeets RJ. Selfefficacy is more important than fear of movement in mediating the relationship between pain and disability in chronic low back pain. Eur J Pain 2011;15:213-9.
9. Crombez G, Vlaeyen JW, Heuts PH, Lysens R. Pain-related fear is more disabling than pain itself: evidence on the role of pain-related fear in chronic back pain disability. Pain 1999;80:329-39.

10. Verbunt JA, Seelen HA, Vlaeyen JW, van der Heijden GJ, Knottnerus JA. Fear of injury and physical deconditioning in patients with chronic low back pain. Arch Phys Med Rehabil 2003;84:1227-32.

11. Vlaeyen JW, Kole-Snijders AM, Rotteveel AM, Ruesink R, Heuts PH. The role of fear of movement/(re)injury in pain disability. J Occup Rehabil 1995;5:235-52.

12. Vincent HK, Seay AN, Montero C, Conrad BP, Hurley RW, Vincent KR. Kinesiophobia and fear-avoidance beliefs in overweight older adults with chronic low-back pain: relationship to walking endurance-part II. Am J Phys Med Rehabil 2013;92:439-45.

13. French DJ, France CR, Vigneau F, French JA, Evans RT. Fear of movement/(re)injury in chronic pain: a psychometric assessment of the original English version of the Tampa Scale for Kinesiophobia (TSK). Pain 2007;127:42-51.

14. Roelofs J, Goubert L, Peters ML, Vlaeyen JW, Crombez G. The Tampa Scale for Kinesiophobia: further examination of psychometric properties in patients with chronic low back pain and fibromyalgia. Eur J Pain 2004;8:495-502.

15. Gheldof EL, Vinck J, Vlaeyen JW, Hidding A, Crombez G. The differential role of pain, work characteristics and pain-related fear in explaining back pain and sick leave in occupational settings. Pain 2005;113:71-81.

16. Helmhout PH, Staal JB, Heymans MW, Harts CC, Hendriks EJ, de Bie RA. Prognostic factors for perceived recovery or functional improvement in non-specific low back pain: secondary analyses of three randomized clinical trials. Eur Spine J 2010;19:650-9.

17. Picavet HS, Vlaeyen JW, Schouten JS. Pain catastrophizing and kinesiophobia: predictors of chronic low back pain. Am J Epidemiol 2002; 156:1028-34.

18. Swinkels-Meewisse IE, Roelofs J, Schouten EG, Verbeek AL, Oostendorp RA, Vlaeyen JW. Fear of movement/(re)injury predicting chronic disabling low back pain: a prospective inception cohort study. Spine (Phila Pa 1976) 2006;31:658-64.

19. Smeets RJ, van Geel KD, Verbunt JA. Is the fear avoidance model associated with the reduced level of aerobic fitness in patients with chronic low back pain? Arch Phys Med Rehabil 2009;90:109-17.

20. Elfving B, Andersson T, Grooten WJ. Low levels of physical activity in back pain patients are associated with high levels of fear-avoidance beliefs and pain catastrophizing. Physiother Res Int 2007;12:14-24.

21. Verbunt JA, Huijnen IP, Koke A. Assessment of physical activity in daily life in patients with musculoskeletal pain. Eur J Pain 2009;13: 231-42.

22. van Weering MG, Vollenbroek-Hutten MM, Hermens HJ. The relationship between objectively and subjectively measured activity levels in people with chronic low back pain. Clin Rehabil 2011;25: 256-63.

23. Trost SG, O'Neil M. Clinical use of objective measures of physical activity. Br J Sports Med 2014;48:178-81.

24. Ciconelli RM, Ferraz MB, Santos W, Meinão I, Quaresma MR. Brazilian-Portuguese version of the SF-36: a reliable and valid quality of life outcome measure. Rev Bras Reumatol 1999;39:143-50.

25. Nusbaum L, Natour J, Ferraz MB, Goldenberg J. Translation, adaptation and validation of the Roland-Morris questionnaire-Brazil Roland-Morris. Braz J Med Biol Res 2001;34:203-10.

26. Roland M, Morris R. A study of the natural history of back pain. Part I: development of a reliable and sensitive measure of disability in low-back pain. Spine (Phila Pa 1976) 1983;8:141-4.

27. Ross RLP. Clinical assessment of pain. In: van Dieen JH, editor. Assessment in occupational therapy and physical therapy. Philadelphia: WB Saunders; 1997. p 123-33.

28. Siqueira FB, Teixeira-Salmela LF, Magalhães LC. Analysis of the psychometric properties of the Brazilian version of the tampa scale for kinesiophobia [Portuguese]. Acta Ortop Bras 2007;15:19-24.

29. de Souza FS, Marinho Cda S, Siqueira FB, Maher CG, Costa LO. Psychometric testing confirms that the Brazilian-Portuguese 
adaptations, the original versions of the Fear-Avoidance Beliefs Questionnaire, and the Tampa Scale of Kinesiophobia have similar measurement properties. Spine (Phila Pa 1976) 2008;33:1028-33.

30. Beck AT, Ward CH, Mendelson M, Mock J, Erbaugh J. An inventory for measuring depression. Arch Gen Psychiatry 1961;4:561-71.

31. Gorenstein C, Andrade L. Validation of a Portuguese version of the Beck Depression Inventory and the State-Trait Anxiety Inventory in Brazilian subjects. Braz J Med Biol Res 1996;29:453-7.

32. Baecke JA, Burema J, Frijters JE. A short questionnaire for the measurement of habitual physical activity in epidemiological studies. Am J Clin Nutr 1982;36:936-42.

33. Sardinha A, Levitan MN, Lopes FL, et al. Translation and cross-cultural adaptation of the Habitual Physical Activity Questionnaire [Portuguese]. Arch Clin Psychiatry (São Paulo) 2010;37:16-22.

34. Troiano RP, Berrigan D, Dodd KW, Masse LC, Tilert T, McDowell M. Physical activity in the United States measured by accelerometer. Med Sci Sports Exerc 2008:40:181-8.

35. Trost SG, McIver KL, Pate RR. Conducting accelerometer-based activity assessments in field-based research. Med Sci Sports Exerc 2005:37:S531-43.

36. Matthews CE, Chen KY, Freedson PS, et al. Amount of time spent in sedentary behaviors in the United States, 2003-2004. Am J Epidemiol 2008; 167:875-81.

37. Portney LG, Watkins MP. Foundations of clinical research: applications to practice. 2nd ed. Upper Saddle River: Prentice Hall; 2000.

38. Smeets RJ, Wade D, Hidding A, Van Leeuwen PJ, Vlaeyen JW, Knottnerus JA. The association of physical deconditioning and chronic low back pain: a hypothesis-oriented systematic review. Disabil Rehabil 2006;28:673-93.

39. Verbunt JA, Smeets RJ, Wittink HM. Cause or effect? Deconditioning and chronic low back pain. Pain 2010;149:428-30.

40. Hagstromer M, Troiano RP, Sjostrom M, Berrigan D. Levels and patterns of objectively assessed physical activity-a comparison between Sweden and the United States. Am J Epidemiol 2010;171: 1055-64.

41. Herbolsheimer F, Schaap LA, Edwards MH, et al. Physical activity patterns among older adults with and without knee osteoarthritis in six European countries. Arthritis Care Res (Hoboken) 2016;68:228-36.

42. Wideman TH, Asmundson GG, Smeets RJ, et al. Rethinking the fear avoidance model: toward a multidimensional framework of painrelated disability. Pain 2013;154:2262-5.

43. Westman AE, Boersma K, Leppert J, Linton SJ. Fear-avoidance beliefs, catastrophizing, and distress: a longitudinal subgroup analysis on patients with musculoskeletal pain. Clin J Pain 2011;27:567-77.

44. Wideman TH, Sullivan MJ. Development of a cumulative psychosocial factor index for problematic recovery following work-related musculoskeletal injuries. Phys Ther 2012;92:58-68.

45. Hasenbring MI, Verbunt JA. Fear-avoidance and endurance-related responses to pain: new models of behavior and their consequences for clinical practice. Clin J Pain 2010;26:747-53.

46. Bunzli S, Smith A, Schutze R, O'Sullivan P. Beliefs underlying pain-related fear and how they evolve: a qualitative investigation in people with chronic back pain and high pain-related fear. BMJ Open 2015;5:e008847. 